ORIGINAL ARTICLE

\section{Management of severe hypertension by nicardipine intravenous infusion in pregnancy induced hypertension after cesarean section}

\author{
Ayano Matsuura ${ }^{1}$, Tamao Yamamoto ${ }^{2}$, Tomoe Arakawa ${ }^{3}$, \\ Yoshikatsu Suzuki ${ }^{1}$
}

Reprint request to:

Tamao Yamamoto, M.D., Ph.D., Department of Obstetrics and Gynecology, Mammy Rose Clinic, Morishita 1, Takasu-Cho, Toyahashi 441-8006, Japan. E-mail: tamao-y@outlook.com

\section{Key words:} gestational hypertension, intravenous nicardipine infusion, preeclampsia, severe hypertension, sliding scale

Received: February 14, 2015

Revised: April 2, 2015

Accepted: April 20, 2015

DOI:10.14390/jsshp.3.28

${ }^{1}$ Department of Obstetrics and Gynecology, Nagoya City West Medical Center, Nagoya, Japan,

${ }^{2}$ Department of Obstetrics and Gynecology, Mammy Rose Clinic, Toyohashi, Japan,

${ }^{3}$ Department of Pharmacy, Nagoya City West Medical Center, Nagoya, Japan

Aim: The aim was to retrospectively investigate whether intravenous administration of nicardipine might be useful for managing blood pressure (BP) after cesarean section in women with severe pregnancy induced hypertension (PIH).

Methods: Fifty-one postpartum women after cesarean section with severe hypertension (systolic BP [SBP] $\geq 160$ $\mathrm{mmHg}$ ) (28 preeclampsia [PE] and 23 gestational hypertension [GH]) were enrolled. According to the modified nicardipine sliding scale procedure, a continuous intravenous infusion of nicardipine at 1 to $6 \mathrm{mg} / \mathrm{h}$ was given to goal (SBP 120-140 $\mathrm{mmHg}$ ) by evaluation every $30 \mathrm{~min}$.

Results: Initial SBPs were $172 \pm 10 \mathrm{mmHg}$ in PE and $175 \pm 11 \mathrm{mmHg}$ in $\mathrm{GH}$. The stable dose of nicardipine was $1.9 \pm 0.8 \mathrm{mg} / \mathrm{h}$ in PE and $1.4 \pm 0.6 \mathrm{mg} / \mathrm{h}$ in $\mathrm{GH}$. The stable dose was greater in PE than in GH. Stable SBPs were $133 \pm 11 \mathrm{mmHg}$ in PE and $136 \pm 11 \mathrm{mmHg}$ in $\mathrm{GH}$. SBP decrease rates were $23 \pm 6 \%$ in PE and $23 \pm 6 \%$ in $\mathrm{GH}$.

Conclusion: In this retrospective study, intravenous administration of nicardipine using a sliding scale appeared useful for decreasing BP in both PE and GH.

\section{Introduction}

Pregnancy induced hypertension (PIH) is classified according to the severity of hypertension, with mild type (blood pressure [BP] ranges from $140 / 90$ to $159 / 109 \mathrm{mmHg}$ ) and severe type (BP $\geq 160 / 110$ $\mathrm{mmHg}$ ), according to the Japan Society for the Study of Hypertension in Pregnancy (JSSHP) criteria. ${ }^{1,2)}$ In the 2009 PIH management guidelines of the JSSHP, the administration of oral antihypertensive drugs for $\mathrm{PIH}$ should be started when the BP is $\geq 160 / 110 \mathrm{mmHg}$ to prevent maternal organ damage (cerebrovascular, cardiac, or renal damage) by prompt antihypertensive treatment. ${ }^{3)}$ As the BP goal, systolic BP (SBP) ranges from 140 to $159 \mathrm{mmHg}$, diastolic BP (DBP) ranges from 90 to 109 $\mathrm{mmHg}$, and mean arterial pressure (MAP) should be decreased by $15 \%$ to $20 \%{ }^{3)}$

The treatment should be switched to intravenous injection therapy, such as nicardipine or hydralazine, when BP control by oral drugs is inappropriate, during labor, and in postpartum women after cesarean section. The guidelines recommend intravenous nicardipine infusion using a sliding scale in both pregnancy and postpartum based on the DBP. In pregnant women, administration should be started when DBP is $\geq 110$ $\mathrm{mmHg}$, with a BP goal of DBP from 90 to $109 \mathrm{mmHg}$. In the postpartum period, administration should be started when DBP is $\geq 90 \mathrm{mmHg}$, and the $\mathrm{BP}$ goal is $\mathrm{DBP}<90$ mmHg. ${ }^{3)}$

The Japan Society of Hypertension (JSH) Guidelines 2014 for the Management of Hypertension state that the basic treatment for PIH is the interruption of pregnancy, 


\section{A. Matsuura et al.}

- If SBP remains $\geq 160 \mathrm{mmHg}$, Nicardipine stock solution $(1 \mathrm{mg} / \mathrm{ml}$ ) is given intravenously with a syringe pump, starting with an initial dose of $1 \mathrm{mg} / \mathrm{h}$.

- The SBP goal is ranged from 120 to $140 \mathrm{mmHg}$.

- BP is measured closely and evaluated after $30 \mathrm{~min}$.

\begin{tabular}{|l|l|l|}
\hline $\mathrm{SBP}(\mathrm{mmHg})$ & Dose of nicardipine $(\mathrm{mg} / \mathrm{h})$ & Evaluation of $\mathrm{BP}$ \\
\hline $\mathrm{SBP} \geq 140$ & $\begin{array}{l}\text { The dose is increased by } 1 \mathrm{mg} / \mathrm{h} \text { to a } \\
\text { maximum dose of } 6 \mathrm{mg} / \mathrm{h} . \\
\text { Call Dr. if the dose is more than } 6 \mathrm{mg} / \mathrm{h} .\end{array}$ & Every $30 \mathrm{~min}$ \\
\hline $120 \leq \mathrm{SBP}<140$ & The dose is maintained. & Every $60 \mathrm{~min}$ \\
\hline $\mathrm{SBP}<120$ & The dose is reduced by $1 \mathrm{mg} / \mathrm{h}$ or stopped. & Every $60 \mathrm{~min}$ \\
\hline
\end{tabular}

Figure 1. The sliding scale of continuous nicardipine intravenous infusion. $\mathrm{BP}$, blood pressure; SBP, systolic blood pressure.

and antihypertensive therapy should be given for maternal protection. It recommends that methyldopa, hydralazine, labetalol, and long-acting nifedipine (only after 20 weeks of gestation) should be used as the first-choice antihypertensive oral drugs. Intravenous administration should be selected when a hypertensive emergency (BP $\geq 180 / 120 \mathrm{mmHg}$ ) occurs. $\left.{ }^{4}\right)$

According to the JSSHP definitions, preeclampsia is present with hypertension and proteinuria, and gestational hypertension is hypertension without proteinuria. ${ }^{1)}$ The pathogenic mechanisms of preeclampsia and gestational hypertension may differ.

In this retrospective study, whether intravenous administration of nicardipine using a sliding scale might be useful for the management of preeclampsia and gestational hypertension was investigated, focusing on changes in SBP.

\section{Methods}

Fifty-one postpartum women after cesarean section with SBP $\geq 160 \mathrm{mmHg}, 28$ with preeclampsia and 23 with gestational hypertension, were enrolled. They included 14 patients ( 4 with preeclampsia and 10 with gestational hypertension) with a hypertensive emergency $(\geq 180$ $\mathrm{mmHg})$.

If SBP remained $\geq 160 \mathrm{mmHg}$, a continuous intravenous infusion of nicardipine at 1 to $6 \mathrm{mg} / \mathrm{h}$ using a sliding scale was given. The SBP goal was $<140 \mathrm{mmHg}$. The sliding scale procedure is shown in Figure 1.

The decrease in SBP was observed during drug administration. When SBP reached the appropriate SBP $(<140 \mathrm{mmHg}$ ) for more than $30 \mathrm{~min}$, this was considered a stable BP. Initial SBP, stable SBP, stable dose of nicardipine, and the $\mathrm{SBP}$ decrease rate (stable $\mathrm{SBP} /$ initial SBP) were evaluated.

This study was retrospectively conducted in the Department of Obstetrics and Gynecology at Nagoya City West Medical Center from 2011 to 2014. The protocol of this study was approved by the Clinical Investigation Ethics Committee of Nagoya City West Medical Center. Informed consent was obtained from each patient. PIH was retrospectively diagnosed 3 months after delivery according to the JSSHP criteria. ${ }^{3)}$

\section{Statistical analysis}

Data are expressed as mean $\pm \mathrm{SD}$. Statistical analysis was performed using Excel Toukei 2012 (SSRI Co., Ltd., Tokyo, Japan). The data were evaluated using the unpaired $t$-test, the Mann-Whitney $U$ test, and the chisquare test comparing the preeclampsia and gestational hypertension groups. The level of significance was set at $P<0.05$.

\section{Results}

\section{Decrease in SBP with drug administration}

Initial SBPs were $174 \pm 10 \mathrm{mmHg}$ in all patients, $172 \pm 10 \mathrm{mmHg}$ in preeclampsia, and $175 \pm 11 \mathrm{mmHg}$ in gestational hypertension (Table 1). All patients reached a stable SBP within $6 \mathrm{~h}(107 \pm 63 \mathrm{~min}$ in all patients, $108 \pm 66 \mathrm{~min}$ in preeclampsia, $106 \pm 60 \mathrm{~min}$ in gestational hypertension). Stable SBPs were $134 \pm 11$ $\mathrm{mmHg}$ in all patients, $133 \pm 11 \mathrm{mmHg}$ in preeclampsia, and $136 \pm 11 \mathrm{mmHg}$ in gestational hypertension (Table 1). The SBP decrease rates were $22 \pm 7 \%$ in all patients, $23 \pm 6 \%$ in preeclampsia, and $23 \pm 6 \%$ in gestational hypertension (Table 1). Stable SBP >140 $\mathrm{mmHg}$ was seen in 10 patients overall (6 with preeclampsia and 4 with gestational hypertension).

The severity of SBP was divided into two levels, with level I SBP from 160 to $180 \mathrm{mmHg}$ and level II SBP at more than $180 \mathrm{mmHg}$ (hypertensive emergency). Level I was present in 24 of 28 preeclampsia cases and in 13 of 23 gestational hypertension cases. The severity of SBP differed between the preeclampsia and gestational hypertension cases $(P=0.015$, chi-square test).

Stable SBPs were similar between the preeclampsia 
Table 1. Decrease in systolic blood pressure (SBP) with drug treatment

\begin{tabular}{|c|c|c|c|c|c|}
\hline & \multirow[b]{2}{*}{ Number } & \multirow{2}{*}{$\begin{array}{l}\text { Initial SBP } \\
\text { (mmHg) }\end{array}$} & \multicolumn{3}{|c|}{ Stable } \\
\hline & & & $\begin{array}{c}\text { SBP } \\
(\mathrm{mmHg})\end{array}$ & $\begin{array}{c}\text { dose } \\
(\mathrm{mg} / \mathrm{h})\end{array}$ & $\begin{array}{l}\text { Rate of decrease } \\
(\%)\end{array}$ \\
\hline$P E$ & 28 & $172 \pm 10$ & $133 \pm 11$ & $1.9 \pm 0.8^{*}$ & $23 \pm 6$ \\
\hline Level I & 24 & $170 \pm 7^{+}$ & $132 \pm 11$ & $1.9 \pm 0.7$ & $22 \pm 6$ \\
\hline Level II & 4 & $187 \pm 10$ & $139 \pm 8$ & $2.3 \pm 1.0$ & $25 \pm 8$ \\
\hline $\mathrm{GH}$ & 23 & $175 \pm 11$ & $136 \pm 11$ & $1.4 \pm 0.6$ & $23 \pm 6$ \\
\hline Level I & 13 & $168 \pm 7^{+}$ & $136 \pm 5$ & $1.2 \pm 0.4^{\dagger}$ & $19 \pm 4^{\dagger}$ \\
\hline Level II & 10 & $186 \pm 5$ & $136 \pm 16$ & $1.7 \pm 0.7$ & $27 \pm 9$ \\
\hline Total & 51 & $174 \pm 10$ & $134 \pm 11$ & $1.7 \pm 0.7$ & $22 \pm 7$ \\
\hline
\end{tabular}

Level I ranges from 160 to $180 \mathrm{mmHg}$, Level II is $\geq 180 \mathrm{mmHg}$. Data are expressed as mean $\pm \mathrm{SD}$. $* P<0.05$ vs GH;

${ }^{+} P<0.05$ vs. Level II.

SBP, systolic blood pressure; PE, preeclampsia; GH, gestational hypertension.

Table 2. Stable doses and reduction rates

\begin{tabular}{|c|c|c|c|}
\hline & \multicolumn{3}{|c|}{ Stable dose of nicardipine } \\
\hline & $1 \mathrm{mg} / \mathrm{h}(n)$ & $2 \mathrm{mg} / \mathrm{h}(n)$ & $3 \mathrm{mg} / \mathrm{h}(n)$ \\
\hline \multicolumn{4}{|l|}{ PE } \\
\hline Level I $(n=24)$ & $24 \pm 7 \%(8)$ & $21 \pm 4 \%(11)$ & $21 \pm 8 \%(5)$ \\
\hline Level II $(n=4)$ & $19 \%(1)$ & $24 \%(1)$ & $29 \pm 10 \%(2)$ \\
\hline \multicolumn{4}{|l|}{$\mathrm{GH}$} \\
\hline Level I $(n=13)$ & $20 \pm 4 \%(10)$ & $16 \pm 1 \%(3)$ & - \\
\hline Level II $(n=10)$ & $27 \pm 9 \%(4)$ & $27 \pm 11 \%(5)$ & $24 \%(1)$ \\
\hline
\end{tabular}

Case numbers are in parentheses. Data are expressed as mean $\pm \mathrm{SD}$.

$\mathrm{PE}$, preeclampsia; $\mathrm{GH}$, gestational hypertension.

and gestational hypertension cases. The SBP decrease rate was greater for level II than for level I in only gestational hypertension.

\section{Dose of nicardipine with stable SBP}

The stable dose of nicardipine was $1.7 \pm 0.7 \mathrm{mg} / \mathrm{h}$ overall, $1.9 \pm 0.8 \mathrm{mg} / \mathrm{h}$ in preeclampsia, and $1.4 \pm 0.6 \mathrm{mg} / \mathrm{h}$ in gestational hypertension. It was greater in preeclampsia than in gestational hypertension $(P=0.0146$, unpaired $t$-test and $P=0.0018$, Mann-Whitney $U$ test; Table 1). The dose of nicardipine was greater in level II $(1.9 \pm 0.7$ $\mathrm{mg} / \mathrm{h}$ vs. $2.3 \pm 1.0 \mathrm{mg} / \mathrm{h}$ in preeclampsia and $1.2 \pm 0.4$ $\mathrm{mg} / \mathrm{h}$ vs. $1.7 \pm 0.7 \mathrm{mg} / \mathrm{h}$ in gestational hypertension) than in level I in only gestational hypertension (Table 1).

In preeclampsia, the dose of nicardipine was greater even though most patients belonged to Level I (24 of 28). Seven patients needed a dose of nicardipine of $3 \mathrm{mg} / \mathrm{h}$. In gestational hypertension, only one of the 10 level II patients needed a dose of nicardipine of $3 \mathrm{mg} / \mathrm{h}$ (Table 2).

\section{Discussion}

JSH Guidelines for the Management of Hypertension 2014 state that antihypertensive drug therapy for PIH should be started at a BP $\geq 160 / 110 \mathrm{mmHg}$. However, if SBP is greater than $180 \mathrm{mmHg}$ or DBP is greater than $120 \mathrm{mmHg}$ in pregnant or postpartum women, antihypertensive treatment should be started under a diagnosis of hypertensive emergency using drugs for intravenous injection. ${ }^{4)}$

The 2009 guidelines of PIH management by the JSSHP state that the treatment should be switched to intravenous injection therapy when BP control by oral drugs is inappropriate, during labor, and postpartum after cesarean section. Intravenous nicardipine infusion using a sliding scale in both pregnancy and postpartum based on the DBP has been recommended. ${ }^{2)}$

In our previous study, just before eclampsia, all patients had a SBP $\geq 160 \mathrm{mmHg}$, while few had DBP $\geq 110 \mathrm{mmHg}$. Furthermore, eclamptic women tended to have a higher SBP than non-eclamptic women, while both 
DBP and MAP were similar to those in non-eclamptic patients. ${ }^{5)}$ Thus, we focused on SBP. If SBP was $\geq 160$ $\mathrm{mmHg}$, a continuous intravenous infusion of nicardipine at 1 to $6 \mathrm{mg} / \mathrm{h}$ using a sliding scale was given, with an SBP goal of less than $140 \mathrm{mmHg}$. Another study might be done by using DBP in the future.

Using the revised nicardipine sliding scale, in most PIH patients with severe hypertension, SBP could be kept under $140 \mathrm{mmHg}$, and it took $2 \mathrm{~h}$ to reach a stable SBP.

The concentration of nicardipine hydrochloride solution is $1 \mathrm{mg} / \mathrm{ml}$. In a hypertensive emergency, administration at $0.5 \mu \mathrm{g} / \mathrm{kg} / \mathrm{min}$ is started, and it ranges from 0.5 to $2 \mu \mathrm{g} / \mathrm{kg} / \mathrm{min}$. In women weighing $50 \mathrm{~kg}$, the starting dose of nicardipine is $1.5 \mathrm{mg} / \mathrm{h}$, and it is increased up to $6 \mathrm{mg} / \mathrm{h}$ according to this equation. In the present study, nicardipine was administered at an average dose of $1.7 \mathrm{mg} / \mathrm{h}$ and ranged from 1 to $3 \mathrm{mg} / \mathrm{h}$.

It is well known that there are differences in pathogenesis between preeclampsia and gestational hypertension. As for severity, preeclampsia is more severe than gestational hypertension, and management of preeclampsia is more difficult than that of gestational hypertension. The NICE guidelines thus recommended different management strategies for preeclampsia and gestational hypertension. ${ }^{6}$

In the present study, in postpartum women given intravenous administration, the more severe the hypertension was, the higher dose of nicardipine was needed in gestational hypertension. In preeclampsia, even though most patients had Level I hypertension, the dose of nicardipine was greater than in gestational hypertension. Postpartum, after interrupted pregnancy, strict management of preeclampsia should be needed. In a previous study, oral administration of labetalol, $\beta$-receptor, and a selective $\alpha_{1}$-receptor blocker effectively decreased BP during pregnancy. However, the effectiveness of labetalol was greater in patients with gestational hypertension $(58 \%)$ than in those with preeclampsia $(27 \%)$. This confirmed that labetalol would be more effective in gestational hypertension than in preeclampsia. ${ }^{7}$ Thus, the pathogenesis of preeclampsia might not be simple. Furthermore, it may be difficult to control BP in preeclampsia compared with gestational hypertension. From our results, it is suggested it might be necessary to terminate the pregnancy earlier in preeclampsia than gestational hypertension. However, it is often difficult to discriminate the two in the clinical course.

In this retrospective study, intravenous administration of nicardipine using a sliding scale appeared useful for the management of both preeclampsia and gestational hypertension.

\section{Acknowledgments}

This work was partly supported by a Grant-in-Aid for Scientific Research from the Japan Society for the Promotion of Science (26462496).

\section{Conflict of interest}

None.

\section{References}

1. Watanabe K, Naruse K, Tanaka K, Metoki H, Suzuki Y. Outline of definition and classification of pregnancy induced hypertension (PIH). Hypertens Res Pregnancy. 2013; 1: 3-4.

2. Japan Society for the Study of Hypertension in Pregnancy (JSSHP). ed. Guideline 2009 for care and treatment of hypertension in pregnancy (PIH). Tokyo: Medical View Co., Ltd., 2009; 179-193.

3. Naruse K, Suzuki Y, Nakamoto O, et al. A Brief Review of the 2009 JSSHP Guidelines for the care and treatment of Pregnancy induced Hypertension. Hypertens Res Pregnancy. 2013; 1: 5-7.

4. Suzuki H. Hypertension in women. Hypertens Res. 2014; 37: 334-338.

5. Matsuura A, Yamamoto T, Watanabe K, Suzuki Y. Characteristics changes of systemic blood pressure seen just before onset of eclampsia. Hypertens Res Pregnancy. 2013; 1: 35-39.

6. National Collaborating Centre for Women's and Children's Health. ed. NICE Clinical Guideline. Hypertension in pregnancy: the management of hypertensive disorders during pregnancy. London: National Institute for Health and Clinical Excellence (NICE), 2011.

7. Matsuura A, Yamamoto T, Arakawa T, Suzuki Y. Oral administration of labetalol might improve not only the blood pressure but also clinical symptoms in Japanese women with gestational hypertension. Hypertens Res Pregnancy. 2014; 2: 82-87. 